\title{
THE ROLE OF ASTRONOMY IN THE HISTORY OF SCIENCE
}

James MacLachlan

Ryerson Polytechnical Institute, 350 Victoria Street, Toronto, Canada M5B 2K3

\section{Introduction}

This historian of science offers a few samples of the kinds of understandings his students will be subjected to. (a) In early times, Britons used careful observations of astronomical events to establish their calendar; (b) In the 4th century BC, Aristotle used the spheres of Eudoxus to establish his cosmological principles; (c) In the second century of our era, Ptolemy made astronomy scientific, partly for the sake of astrological predictions; (d) In the fifteenth century, Columbus used crude astronomical observations to find latitude. (e) In the sixteenth century, Copernicus revised Ptolemaic astronomy in order to improve its fit with Aristotelian cosmology, and in the process challenged that cosmology; (f) Kepler used Tycho's more precise data to destroy heavenly circularity; (g) In the early seventeenth century, Galileo based his renovation of motion studies on the investigative style he learned from Ptolemy, coupled with mathematics learned from Euclid and Archimedes.

Segments of history such as these are intended to demonstrate that astronomy has had contacts with numerous other aspects of life for many centuries. Astronomers should be able to interact with historians to the mutual benefit of both.

\section{Use of the History of Science}

I believe that history of science is useful in introducing certain topics of science, partly because it can pose problems in their original settings, and partly because it can often introduce complexity gradually.

Many of my students are majoring in technologies such as electrical and mechanical. They take a course in history of science and technology as an option in their third year (of four). One of my major motivations in teaching them such a course is to make them aware of the struggles innovators go through in order to produce change. Another is to try to show science and technology as intimately related to numerous other aspects of human activities. In this process I use several astronomical examples. They are helpful because of humans' eternal fascination with astronomy, and because I need them in order to account for other developments in science, particularly in physics.

The first example $I$ introduce is based on the researches of Alexander Thom (Ruggles, 1988) in Britain over the past 50 years. Long before they could write, early Britons used stone markers to record extreme positions of the sun and the moon. I have described this in my textbook on the history of science and technology, Children of Prometheus (preliminary edition: Toronto, Wall \& Thompson, 1988), 
p. 36. I suggest that these megalithic astronomical monuments were erected for religious purposes connected with the Britons' concern for the sun's control over the seasons.

By the time of Aristotle, Greek mathematicians possessed astronomical data compiled in Babylon, and a fine set of analytical tools (ibid., p. 37). After Eudoxus had done his best to use nested spheres to match the data, Aristotle adopted Eudoxus's basic model as the foundation of his cosmology. In the process, Aristotle laid down principles that influenced European thought for most of the next 2000 years. In particular, he made a sharp distinction between the sublunar and astral spheres.

Ptolemy may be called the first fully-fledged scientist for his concern to provide models of the planetary orbits that actually fitted observed positions. As opposed to being largely empirical like the Babylonians, or mainly theoretical like Aristotle, Ptolemy combined the two into an effective predictor of planetary positions ( $i b i d$., p. 38).

According to Noel Swerdlow (1984), Copernicus's main motivation for altering the Ptolemaic scheme was to make an astronomical model that would be more consistent with Aristotle's principles. That is, Copernicus reluctantly adopted motions of the Earth in order to avoid the mechanical absurdity of the equant (ibid., pp. 88-91).

Kepler, on the other hand, reluctantly adopted elliptical orbits in order to fit Tycho Brahe's data as closely as possible. Kepler also sought to create a physics of the heavens, but he was premature (ibid., pp. 93-95). The route to a universal physics with Newton (ibid., pp. 124-132) lay through Galileo's mathematizing of motion (Drake, 1978), which he did by using astronomy as his model for science (ibid., pp. 108-109).

By examples such as these, I suggest various ways in which science has developed during the past centuries. In the process, there is some chance that my students may also pick up a few items of astronomical knowledge!

\section{References}

Drake, Stillman, Galileo at Work (University of Chicago Press, 1978)

Ruggles, Clive, ed. Records in Stone (Cambridge University Press, 1988)

Swerdlow, N.M. and O. Neugebauer, Mathematical Astronomy in Copernicus's “de Revolutionibus" (Springer-Verlag, 1984) 